\title{
Effectiveness of refractive error correction for people with oculocutaneous albinism in Nepal
}

\author{
Arjun M Bhari', Kabindra Bajracharya ${ }^{2}$, Hari B Thapa ${ }^{3}$, Maria Gautam4, Araniko Pandey5, \\ Ken Bassett ${ }^{6}$ \\ ${ }^{1}$ Consultant Pediatric Ophthalmologist, ${ }^{2}$ Assistant Professor and Pediatric Ophthalmologist, ${ }^{3}$ Optometrist, Department of \\ Pediatric Ophthalmology and Strabismus, Lumbini Eye Institute, Bhairahawa, ${ }^{4}$ Ophthalmologist, Bharatpur Eye Hospital, \\ Bharatpur, ${ }^{5}$ Ophthalmologist, Lumbini Eye Institute, ${ }^{6}$ Director, Seva Foundation, Canada
}

Background: Albinism is commonly associated with high refractive errors, but some clinicians are reluctant to prescribe glasses because reduced vision persists due to additional non-refractive visual problems. Aims and Objective: The purpose of this study was to evaluate the effectiveness of glasses in people with oculocutaneous albinism in Nepal. Materials and Methods: People with Oculocutaneous albinism (OCA) were prospectively examined through an outreach program of Lumbini Eye Institute, Nepal. Glasses were prescribed to determine the objective improvement in visual acuity (VA) and strabismus. Compliance with spectacles wear was assessed by telephone contact after 3 weeks and categorized as excellent: $>75 \%$ of awake hours; good: $50-75 \%$ of awake hours; fair: $26-50 \%$ of awake hours and poor: $<25 \%$. Results: Thirty one people $(65 \%$ male) mean age 18 years (range: 3 to 50) with OCA were examined. Mean refractive correction was $-0.40 \pm 4.3$ diopters spherical equivalents (range: -11.0 to $+7.0 \mathrm{D}$ ). Mean visual acuity at distance was $0.9 \pm 0.28(6 / 50)$ corrected and $1.150 .31(5 / 60)$ uncorrected $(P=0.000)$ in 62 eyes. Mean neat VA was $1.74 \pm 0.89 \mathrm{M}$ corrected and $2.06 \pm 1.20 \mathrm{M}$ uncorrected $(P=0.004)$. Forty eight per cent (15 people) had fusion with or without glasses and one had fusion only with glasses. Compliance was excellent in $52 \%(16)$, fair in $26 \%(8)$, good in $12 \%(4)$, and poor in $10 \%(3)$. Conclusion: Providing eye glasses resulted in a clinically and functionally significant improvement in visual acuity and function in people with OCA.

Key words: Albinism, Refractive error, Glasses, Visual acuity improvement

\section{INTRODUCTION}

Albinism is an inherited disorder involving a defective synthesis of melanin from tyrosine resulting from mutation of one or more associated genes. ${ }^{1}$ This result in a reduction in or absence of melanin in various parts of the body, particularly hair, skin and eyes. Albinism is universal, although unevenly distributed ${ }^{2}$ with an estimated incidence of approximately one in $20,000^{2}$ with no sex difference. ${ }^{3,4}$

The phenotypic classification of albinism is either oculocutaneous albinism (OCA) or ocular albinism (OA). OCA people have reduced melanin in the eyes, skin and hair, whereas OA involves reduced or absent melanin only in the eyes. ${ }^{5}$ OCA is further categorized as incomplete OCA (reduced melanin) or complete OCA (absent melanin). OCA affects an estimated one in 17,000 people in Nepal. ${ }^{6}$

OCA has significant optical defects including large corneal astigmatism, foveal hypoplasia and abnormal decussation of optic nerve fibers. The abnormal decussation is thought to determine the neuronal target specificity and misrouting of retinogeniculate projections resulting in strabismus and reduced stereoscopic vision. ${ }^{3,4,7}$ Consequently, VA is generally reduced, leading to visual impairment, and cases tend to have severe photophobia. High refractive errors, including astigmatism occurs frequently. ${ }^{8}$ 
Most Nepalese live in rural areas isolated from health care services with minimal knowledge of medical conditions. People with albinism therefore remain poorly understood often caught in a world of spiritual beliefs and superstition. Those that do seek assistance seldom receive glasses because most Nepali professionals presume they have poor potential for visual improvement. ${ }^{6}$

In this study, we determined if the glasses improved VA and visual function in people with OCA.

\section{MATERIALS AND METHODS}

This was a cross sectional descriptive community based study conducted between January $1^{\text {st }} 2016$ to March $30^{\text {th }}$ 2016. People with OCA were recruited from two community based programs in Western Nepal. One was held in Nepalgunj communicating with Albino-Nepal Organization. The organization collected 17 people with 15 accepting enrollment. Sixteen people with OCA were recruited through a community program conducted in Butwal in collaboration with the Nepal Association of Blindness, Rupandehi district. The diagnostic criteria for OCA were: presence of iris transillumination, retinal hypopigmentation and depigmentation of the skin, hair, and nails. ${ }^{5,9}$

The 31 participants were provided with photo-chromatic distant glasses, free of cost with financial support of SEVA, Nepal. Out of 31 participants, 3 already had glasses. They were re-evaluated and prescribed new glasses with photochromatic lenses.

Demographic profile, history of chief complaints, previous use of low vision devices and use of any refractive correction were recorded. Unaided and aided VA was measured by using $\log M A R$ illiterate and literate charts (whichever appropriate) along with retinoscopy and subjective refraction. Extra ocular motility, strabismus, fusion and nystagmus were assessed. Anterior and posterior segment evaluation was performed under mydriasis.

Cycloplegic refraction was carried out 30 min after instillation of three drops of $1 \%$ cyclopentolate $5 \mathrm{~min}$ apart. Participants who had emmetropia were excluded from the study.

Participants were interviewed by phone 3 weeks after glasses dispensed. Compliance with glasses wear was recorded as excellent ( $>75 \%$ of awake hours), good $(50-75 \%)$, fair $(26-50 \%)$, or poor $(<25 \%)$ according to the information given by participants or parents. They were asked unstructured open ended questions about the impact of glasses on their quality of life and activities of daily living. The study was approved by the institutional review board at Lumbini Eye Institute.

\section{RESULTS}

Thirty-one patients with OCA were included, mean age 18.5 years (median17 years) with $20(65 \%)$ male and $11(35 \%)$ female; male: female ratio1.82:1. The largest proportions of participants (39\%) were between 16 and 25yrs (Table 1).

Using world health organization classification based on best corrected distance visual acuity, $5 \%, 73 \%, 16 \%$ and $6 \%$ of 62 eyes had normal vision, moderate VI, severe VI and blindness respectively (Table 2).

Glasses resulted in a significant improvement in mean distance VA (mean acuity: $1.15 \pm 0.308$ and $0.93 \pm 0.279$ $\log$ MAR) for uncorrected and corrected, respectively (Table 3).

Prescription of new glasses resulted in a statistically significant improvement in mean near VA at $2.06 \mathrm{M} \pm 1.20$

\begin{tabular}{|c|c|c|c|c|}
\hline \multirow[t]{2}{*}{ Age (years) } & \multicolumn{2}{|c|}{$\operatorname{Sex}(N)$} & \multirow[t]{2}{*}{ Total (N) } & \multirow[t]{2}{*}{ Percentage (\%) } \\
\hline & Male & Female & & \\
\hline $0-5$ & 4 & 1 & 5 & 16.1 \\
\hline $6-15$ & 4 & 4 & 8 & 25.8 \\
\hline $16-25$ & 7 & 5 & 12 & 38.7 \\
\hline $26-35$ & 3 & 0 & 3 & 9.7 \\
\hline $36-50$ & 2 & 1 & 3 & 9.7 \\
\hline Total & $20(65 \%)$ & $11(35 \%)$ & 31 & 100.0 \\
\hline
\end{tabular}

Mean $18.56 \pm 12.166$ years, $95 \% \mathrm{Cl}: 14.10-23.03$, Range: $3-50$

\begin{tabular}{|c|c|c|c|}
\hline \multirow[t]{2}{*}{ Distance VA } & \multicolumn{2}{|c|}{$\mathrm{n}(\%)$} & \multirow{2}{*}{$\begin{array}{l}\text { Classification } \\
\text { of } \mathrm{VI}\end{array}$} \\
\hline & $\begin{array}{c}\text { Presenting } \\
\text { VA, }\end{array}$ & $\begin{array}{c}\text { Corrected } \\
\text { VA, }\end{array}$ & \\
\hline $6 / 6-6 / 18$ & 0 & $3(5)$ & Normal \\
\hline$<6 / 18-6 / 60$ & $30(48)$ & $45(73)$ & $\begin{array}{l}\text { Moderate } \\
\text { visual } \\
\text { impairment }\end{array}$ \\
\hline$<6 / 60-3 / 60$ & $19(31)$ & $10(16)$ & $\begin{array}{l}\text { Severe visual } \\
\text { impairment }\end{array}$ \\
\hline$<3 / 60-P L$ & $13(21)$ & $4(6)$ & Blindness \\
\hline $\begin{array}{l}\text { Mean distance } \\
\text { VA in logMAR }\end{array}$ & $1.15 \pm 0.31$ & $0.94 \pm 0.28$ & \\
\hline
\end{tabular}




\begin{tabular}{|c|c|c|c|c|c|c|}
\hline & Maximum & Minimum & Median & Mean $\pm S D$ & $95 \% \mathrm{Cl}$ for mean & p \\
\hline UCDVA & 0.6 & 1.8 & 1.08 & $1.15 \pm 0.308$ & $1.07-1.23$ & 0.000 \\
\hline BCDVA & 0.48 & 1.8 & 0.9 & $0.93 \pm 0.279$ & $0.87-1.01$ & \\
\hline
\end{tabular}

$\begin{aligned} & \text { Table 4: Near visual acuity by eye by distance ; } \\
& 62 \text { eyes }\end{aligned}$
\begin{tabular}{lcc} 
Near visual \\
acuity (meters) & \multicolumn{2}{c}{$\mathbf{n}(\%)$} \\
\cline { 2 - 3 } & $\begin{array}{c}\text { Presenting visual } \\
\text { acuity }\end{array}$ & $\begin{array}{c}\text { Corrected visual } \\
\text { acuity }\end{array}$ \\
\hline 1 & $11(18)$ & $17(27)$ \\
1.25 & $17(27)$ & $15(24)$ \\
1.5 & $2(3)$ & $2(3)$ \\
1.6 & 0 & $2(3)$ \\
2 & $18(29)$ & $16(26)$ \\
2.25 & 0 & $2(3)$ \\
2.5 & $2(3)$ & 0 \\
3.2 & $2(3)$ & $4(6)$ \\
4 & $4(6)$ & $2(3)$ \\
4.5 & $2(3)$ & $2(3)$ \\
5 & $4(6)$ & 0 \\
Total & & $1.74 \pm 0.89$ \\
Mean VA & $2.06 \pm 1.20$ & \\
\hline
\end{tabular}

and $1.74 \mathrm{M} \pm 0.89$ uncorrected and corrected, respectively (paired samples $\mathrm{t}$-test $=0.004$ ) (Table 4).

Astigmatism was present in 2/3 of people. Hypermetropic astigmatism was most prevalent ( $\mathrm{n}=24,39 \%)$, followed by myopic astigmatism $(n=18,29 \%)$, simple myopia $(n=14$, $23 \%$ ) and hypermetropia $(n=6,10 \%)$ (Table 5). The refractive errors ranged from $+7.00 \mathrm{D}$ to $-11.00 \mathrm{D}$ spherical equivalent with a mean of $-0.40 \pm 4.36$ diopters.

Forty eight percent (15 patients) had fusion with or without glasses and one had fusion only with glasses. The mean strabismus at near and distance was significantly improved with distance correction.

Glasses wear compliance was excellent in 52\% (16 patients), fair in 26\% (8 patients), good in 12\% (4 patients), and poor in $10 \%$ (3 patients) (Figure 1).

The sample included 21 (68\%) students. Among them, 19 had near VA $\geq 2 \mathrm{M}$ with correction. Seven students had significantly improved near VA with correction. Two students needed low vision devices for near work.

Glasses resulted in a significant improvement in strabismus from a mean deviation of 16.3 PD without glasses to 13 PD with glasses for distance vision, and from 16.1 PD without glasses to 13.1 PD with glasses for near vision. Glasses improved alignment at either distance or near fixation by more or equal to $10 \mathrm{PD}$ in 6 cases. Glasses

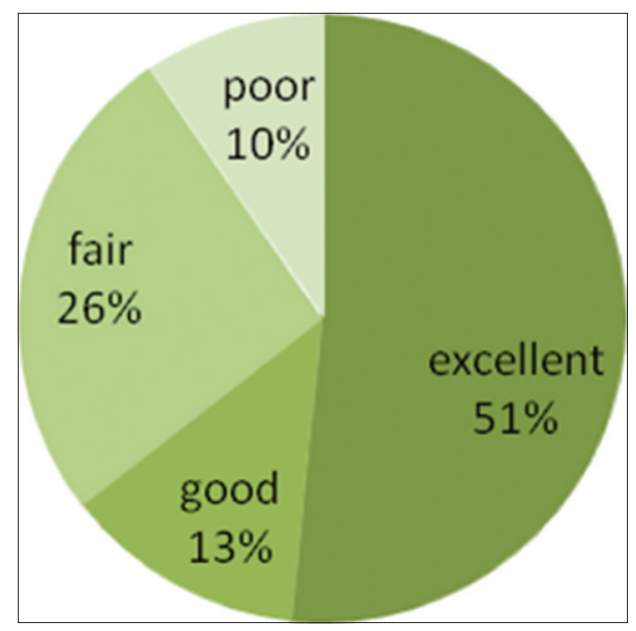

Figure 1: Spectacle wear compliance

also improved the angle of esotropia in patients with high hyperopia.

Twenty eight people reported that they travelled better in sunlight (6), had improved performance of daily living activities like reading (15) or both functions (7). Three participants did not feel any difference with the glasses in their life and did not like their appearance with glasses (Table 7).

Among 5 participants with high myopia (>6.00ds) all reported excellent compliance. One case was a 42 year old farmer with -8.00 ds refractive error and unaided distance visual acuity 3/60 in both eyes. After correction, his distance visual acuity was $6 / 48$ in both eyes. The compliance with glasses was reported as excellent for farming as well as for walking in sunlight.

Another case was a 3 year male child presenting with distance VA of 4/60 in both eyes. After correction, his VA was 6/60 with an improvement in near vision from $4 \mathrm{M}$ to $2 \mathrm{M}$. As a result the child could read his textbook. He used glasses only for reading and not for distance as he was not encouraged to use his new glasses constantly.

\section{DISCUSSION}

Individuals with oculocutaneous albinism have visual impairment that compromises their social interactions 


\begin{tabular}{|c|c|c|c|c|c|c|}
\hline Refractive error & $\mathbf{N}(\%)$ & Mean & Standard deviation & $95 \% \mathrm{Cl}$ & Minimum & Maximum \\
\hline Myopia & $14(23)$ & -0.40 & 4.36 & $-1.50-0.70$ & -11 & 7.00 \\
\hline Hypermetropia & $6(10)$ & & & & & \\
\hline Myopic astigmatism & $18(29)$ & & & & & \\
\hline Hypermetropic astigmatism & $24(39)$ & & & & & \\
\hline Total & $62(100)$ & & & & & \\
\hline
\end{tabular}

\begin{tabular}{|c|c|c|c|}
\hline $\begin{array}{l}\text { Strabismus in } \\
\text { mean }\end{array}$ & $\begin{array}{l}\text { Without } \\
\text { glasses }\end{array}$ & $\begin{array}{c}\text { With } \\
\text { glasses }\end{array}$ & p-value (2-tail) \\
\hline $\begin{array}{l}\text { Near (prism } \\
\text { diopters) }\end{array}$ & $16.1 \pm 18.5$ & $13.1 \pm 17.1$ & 0.001 \\
\hline $\begin{array}{l}\text { Distance (prism } \\
\text { diopters) }\end{array}$ & $16.3 \pm 18.7$ & $13.0 \pm 17.0$ & 0.001 \\
\hline
\end{tabular}

\begin{tabular}{lc} 
Table 7: Quality of life open ended \\
questions ( $\mathbf{n = 3 1 )}$ & Frequency \\
\hline Quality of life & 6 \\
\hline $\begin{array}{l}\text { Able to get around in sunlight very well } \\
\text { Satisfy with the glasses to perform their daily }\end{array}$ & 15 \\
living activities (distance task=7, playing=1, & \\
reading=6, outdoor work=1) & 7 \\
$\begin{array}{l}\text { Both able to get around sunlight and satisfied } \\
\text { with glasses to perform their daily living activities }\end{array}$ & 3 \\
$\begin{array}{l}\text { Did not feel any difference with the glasses in } \\
\text { their life }\end{array}$ & \\
\hline
\end{tabular}

compared to their peers, resulting in cognitive, emotional, social and academic difficulties. ${ }^{10}$ In our study, 95\% of the eyes had visual impairment with the majority $(73 \%)$ having moderate visual impairment and $6 \%$ blind, similar to Eballe et $\mathrm{al}^{11}$, Another study in Nepal reported that $56 \%$ of the eyes were moderate visual impairment and $8 \%$ were blind $^{10}$. In our study, hypermetropic astigmatism was most prevalent $(n=24,39 \%)$ but in another study in Nepal by S.Khanal ${ }^{10}$ et al, myopic astigmatism was most common $(\mathrm{n}=17,34 \%)$.

Several studies have also reported that albinism is associated with high spherical and astigmatic refractive errors. ${ }^{12}$ In our study, $68 \%$ of total eyes were associated with astigmatism and mean VA improved at distance from $1.15 \pm 0.308$ to $0.93 \pm 0.279 \log$ MAR with glasses that was similar to Safal Khanal et al..$^{10}$

In our study, 48\% (15 patients) had fusion with or without glasses and one only with glasses. None had stereopsis either with or without glasses. A similar sized study in the United States reported two individuals who gained and one who lost fusion with glasses. ${ }^{13}$

The US study showed a higher spectacle compliance during follow up visits to the outpatient clinic with excellent in
29 patients $(83 \%)$, fair in $4(11 \%)$ and poor in $2(6 \%)$ in an urban setting where most. ${ }^{13}$ Our study may have lower compliance because this rural population, in contrast to the US population, were wearing glasses for the first time and had no active follow up program to assist with fitting of frames.

\section{CONCLUSION}

There was significant improvement in visual acuity and function following optical correction and alignment in people with albinism, despite overall subnormal acuity. Refractive correction should be encouraged for people with albinism.

\section{ACKNOWLEDGEMENT}

We would like to grateful thanks to SEVA, Nepal for providing the financial support for the project.

\section{REFERENCES}

1. Summers CG. Albinism: classification clinical characteristic and recent findings. Optom Vis Sci. 2009; 86: 659-662.

2. Wildsoet CF, Oswald PJ and Clark S. Albinism: its implications for refractive development. Invest Opthalmol Vis Sci. 2000; 41: 1-7.

3. Carden SM, Boissy RE, Schoettker PJ and Good WV. Albinism: modern molecular diagnosis. $\mathrm{Br} \mathrm{J}$ Ophthalmol. 1998; 82: 189-195.

4. Gronskov K, EK J and Brondum-Nielsen K. Oculocutaneous albinism. Orphanet J Rare Dis. 2007; 2: 43.

5. Abadi $R$ and Pascal $E$. The recognition and management of albinism. Ophthalmic Physiol Opt. 1989; 9: 3-15.

6. Bibbi Abruzzini. Feature: Nepal's albinos caught between reality, myth', FollowXinhuanet. (http://news.xinhuanet.com/english/ world/2014-10/09/c_133702376.htm)

7. Biswas $S$ and Lloyd IC. Oculocutaneous albinism. Arch Dis Child. 1999; 80: 565-569.

8. Spedick MJ and Beauchamp GR. Retinal vascular and optic nerve abnormalities in albinism. J Pediatr Ophthalmol Strabismus. 1986; 23: 58-63.

9. Summers CG. Vision in albinism. Trans Am Ophthalmol Soc. 1996; 94: 1095-1155.

10. Safal Khanal, Amrit Pokhrel and Himal Kandel. Visual deficits in Nepalese patients with oculocutaneous albinism. Journal of Optometry. 2016; 9: 103-9. 
11. Eballe AO, Mvogo CE, Noche C, Zoua MEA and Dohvoma AV. Refractive error in Cameroonians diagnosed with complete oculocutaneous albinism. Cli Ophthalmol. 2013; 7: 1491.

12. Silver J. Low vision aids in the management of visual handicap. $\mathrm{Br}$
J Physiol Opt. 1977; 31: 47-87.

13. Jill Anderson et al. Efficacy of spectacles in persons with albinism. American Association for Pediatric Ophthalmology and Strabismus. 2004; 8: 515-20.

\section{Authors Contribution:}

AMB- Concept, design of the study, reviewed literature, collected data, manuscript preparation, editing and revision of the manuscript; KB- editing and revision of the manuscript; HBT- Design, statistical analysis; MG- Review literature; AP- editing and revision of manuscript; KeB- Reviewed literature, manuscript preparation.

\section{Orcid ID:}

Dr. Arjun M Bhari: http://orcid.org/0000-0003-2753-5155

Dr. Kabindra Bajracharya: (io http://orcid.org/0000-0002-1742-9220

Dr. Hari B Thapa:(i) http://orcid.org/0000-0002-2132-0666

Dr. Maria Gautam: http://orcid.org/0000-0002-8206-9786

Dr. Araniko Pandey: http://orcid.org/0000-0002-0791-293X

Dr Ken Bassett:(i) http://orcid.org/0000-0001-9414-562X 